\title{
Hematology and Iron Status Evaluation Based on Donation Characteristics in Dr. Sardjito Hospital, Yogyakarta
}

\author{
Fuad Anshori, Tri Ratnaningsih, Teguh Triyono \\ Department of Clinical Pathology, Faculty of Medicine, Gadjah Mada University/Dr. Sardjito Hospital, Yogyakarta, Indonesia. E-mail: \\ fuad.anshori@mail.ugm.ac.id
}

\begin{abstract}
Blood donation will reduce iron storage in the body. A high frequency of donations and short interval inter-donations may increase the risk of iron deficiency. In Indonesia, detection of iron deficiency in blood donors is not a routine procedure. Therefore, the comparison of hematology and iron status based on donor characteristics is not widely known. For a month, this study was a cross-sectional study conducted at the Blood Transfusion Service Unit, Dr. Sardjito Hospital. Subjects were routine blood donors who met the criteria for donor selection; however, subjects were excluded if the CRP level was > $10 \mathrm{~g} / \mathrm{L}$ and had a history of iron supplementation. Subjects were divided based on donation frequency and blood donation interval. The Kruskal-Wallis test was used to compare variables among groups with a statistical significance of $p<0.05$. This study involved 145 subjects who met the criteria. Blood donations more than 20 times showed the lowest ferritin levels and iron saturation (16.9 $\mathrm{ng} / \mathrm{mL}$ and $15.08 \%)$. Ferritin levels were also increased in line with the donation interval $(35.5 \mathrm{ng} / \mathrm{mL}$; $75.3 \mathrm{ng} / \mathrm{mL} ; 92.7 \mathrm{ng} / \mathrm{mL}$ every three months). However, the hematological parameters and iron saturation did not differ significantly based on the donation interval. Hematological parameters are easy and fast procedures but have limitations in the early detection of iron deficiency. Serum ferritin has higher specificity, but its level is affected by inflammatory conditions. Ferritin levels were consistently at the lowest level in the subjects with the highest risk of iron deficiency compared to hematologic and iron saturation parameters.
\end{abstract}

Keywords: Iron deficiency, blood donation, hematology, iron status

\section{INTRODUCTION}

World Health Organization (WHO) reported that 112.5 million units of blood had been donated annually with a total donation of 10 to 30 donations per 1000 population. ${ }^{1}$ However, safety and health have not been completely monitored in each blood transfusion unit. For every blood donation with a volume of $450-500 \mathrm{~mL}$, a donor will lose $200-250 \mathrm{mg}$ of iron from his body. ${ }^{2}$ It is equivalent to losing $30 \%$ of iron reserves in males or nearly $80 \%$ of iron stores in females. ${ }^{3}$ Repeated blood donations, short donation intervals, female gender, and low body weight predispose a donor to develop iron deficiency. If the loss of iron is not compensated by adequate iron intake, it will disrupt iron homeostasis. ${ }^{4}$

Iron deficiency in the blood donor population is one of the health problems that may often not be revealed. However, iron status is not routinely tested on donors due to financial reasons. ${ }^{5}$ Accurate detection of iron deficiency requires laboratory tests with good diagnostic capabilities. Routine hematology tests, ferritin, and iron saturation are widely used despite varying diagnostic capabilities. Previous studies have shown that ferritin levels had a close relationship with the frequency and interval of blood donation. ${ }^{6}$ The attempt to maintain the safety and security of routine blood donors, detecting iron deficiency is necessary immediately after a follow-up such as iron supplementation. Therefore, this study was aimed to evaluate the hematologic and iron status studies of a blood donor population with donation characteristics across a varied spectrum of risks for iron deficiency.

\section{METHODS}

This research was an observational analytic study with a cross-sectional design that involved routine blood donor subjects who came to the Blood Transfusion Service Unit at Dr. Sardjito Hospital in September 2019 by consecutive sampling. The issue who met the donor selection criteria with a history of donations at least twice a year and signed informed consent were recruited in this study. Study subjects who had marked signs of inflammation and CRP level $>6 \mathrm{mg} / \mathrm{L}$ were excluded from this study. Venous 
blood samples were obtained at the end of blood donation and inserted into a tube with a clot activator and EDTA tube. The iron status test, including serum iron and Total Iron Binding Capacity (TIBC), was measured using the spectrophotometry method. In contrast, ferritin and CRP were measured by the ECLIA method using the Cobas ${ }^{\circledR} 6000$ Automated Immunochemical Analyzer (Roche Diagnostic, Germany, Inc.). Serum iron saturation of transferrin was calculated by dividing the serum iron with TIBC and multiplied by $100 \%$. Hematological parameters were measured using the Siemens ${ }^{\circledR}$ Advia 2120.

The research subjects were divided based on the characteristics of their blood donations, such as the frequency of blood donations (1-5 times, $6-10$ times, 11-20 times, and $>20$ times) and the blood donor interval ( $<3$ months, 3-6 months and $>6$ months). The results of hematology, ferritin, and iron saturation were presented in a boxplot graph. They were statistically analyzed using the Kruskal-Wallis test to determine the difference in variables in each group. A p-value $<0.05$ indicated statistical significance.

This research had received approval from the Health Research Ethics Committee of MHREC Faculty of Medicine, Public Health and Nursing, Gadjah Mada University/Dr. Sardjito Hospital, Yogyakarta with number of KE/FK/0690/EC/2019.

\section{RESULTS AND DISCUSSIONS}

This study involved 145 normal blood donor subjects 18-60 years old by age with a median age of 31 years characteristics as shown in Table 1 . The subjects of the study were dominated by male blood donors (71.7\%). In addition, the highest frequency of blood donation was found in the group 6-10 times as

Table 1. Characteristics of subjects

\begin{tabular}{lc}
\hline \multicolumn{1}{c}{ Variable } & $\mathbf{N}=\mathbf{1 4 5}$ subjects \\
\hline Age $($ year) & $31(18-60)$ \\
Gender & \\
$\quad$ Male, $\mathrm{n}(\%)$ & $104(71.7 \%)$ \\
$\quad$ Female, $\mathrm{n}(\%)$ & $41(28.3 \%)$ \\
Frequency of blood donor & \\
$\quad 2-5$ times, $\mathrm{n}(\%)$ & $36(24.8 \%)$ \\
6-10 times, $\mathrm{n}(\%)$ & $52(35.8 \%)$ \\
$\quad 11-20$ times, $\mathrm{n}(\%)$ & $42(29.6 \%)$ \\
$>20$ times, $\mathrm{n}(\%)$ & $15(10.8 \%)$ \\
Interval of blood donation & \\
$\quad<3$ months, $\mathrm{n}(\%)$ & $100(69 \%)$ \\
$\quad 3-6$ months, $\mathrm{n}(\%)$ & $43(29.7 \%)$ \\
$\quad>6$ months, $\mathrm{n}(\%)$ & $2(1.4 \%)$ \\
Iron saturation $(\%)^{*}$ & $24(6-69)$ \\
Ferritin $(\mathrm{ng} / \mathrm{mL})^{*}$ & $40.4(4.9-357,8)$ \\
CRP (mg/L)* & $1.2(0.1-5.9)$ \\
\hline
\end{tabular}

*Expressed as median (min-max)

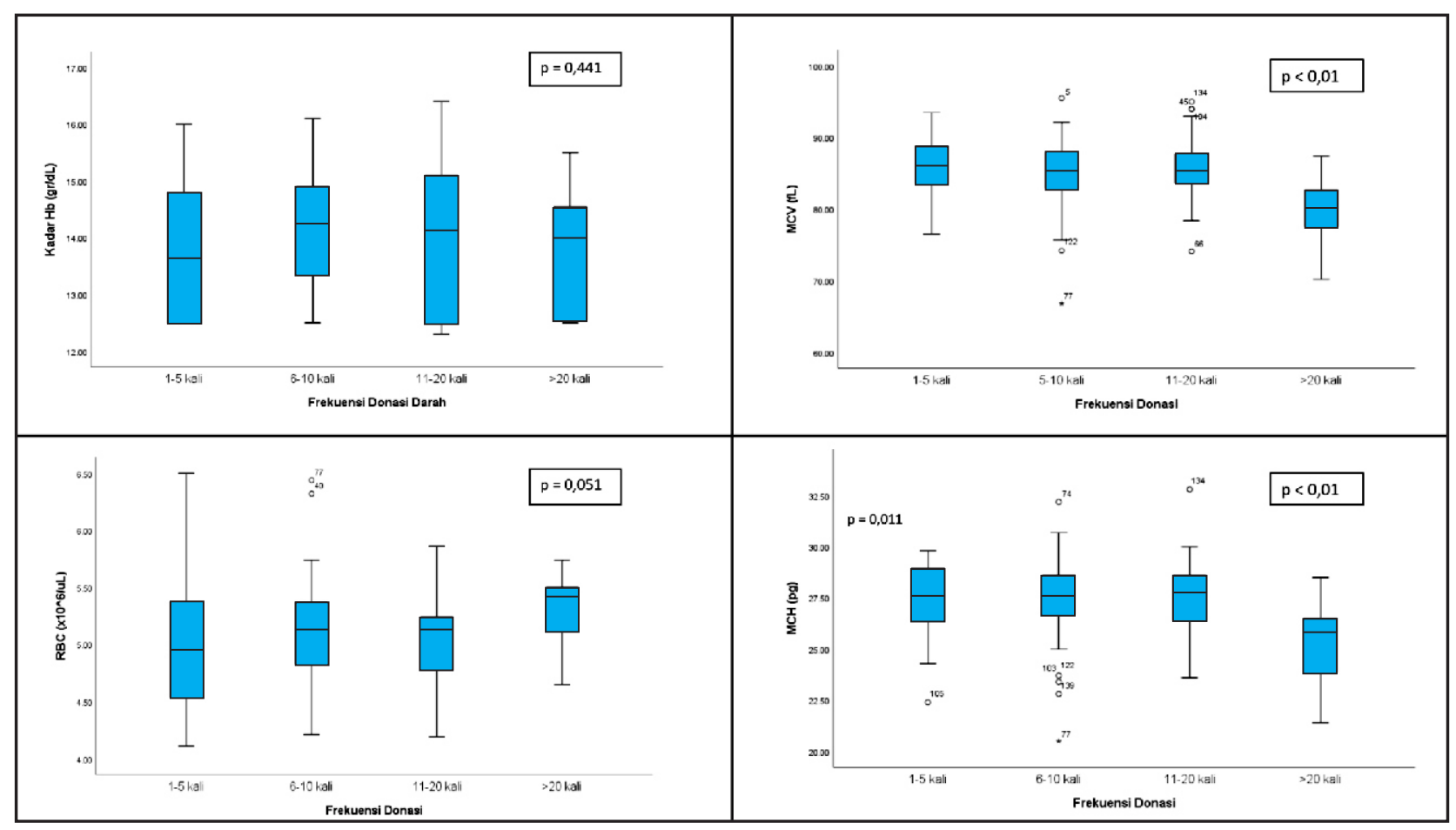

Figure 1. Hematology parameter based on blood donation frequency 
many as 52 subjects (35.8\%), and the most frequent interval between donations was in the $<3$ months group (69\%)

Subjects in this study had a median serum iron saturation of $24 \%$ with a range of $6 \%$ to $69 \%$ and a median ferritin of $40.4 \mathrm{ng} / \mathrm{mL}$ with 6 to $69 \mathrm{ng} / \mathrm{mL}$. In addition, the median CRP level in the subjects of this study was $1.2 \mathrm{mg} / \mathrm{L}$ with a range of 0.1 to $5.9 \mathrm{mg} / \mathrm{L}$.
Hematological tests in the study subjects showed that only the Mean Corpuscular Volume (MCV) parameter significantly differed between the blood donation frequency groups. Median MCV levels decreased significantly with increasing frequency of blood donations ( $86.1 \mathrm{fL}$ vs. $85.2 \mathrm{fL}$ vs. $85.8 \mathrm{fL}$ vs $80.7 \mathrm{fL}$; $p=0.002)$. The same result was also found in the median level of Mean Corpuscular Hemoglobin

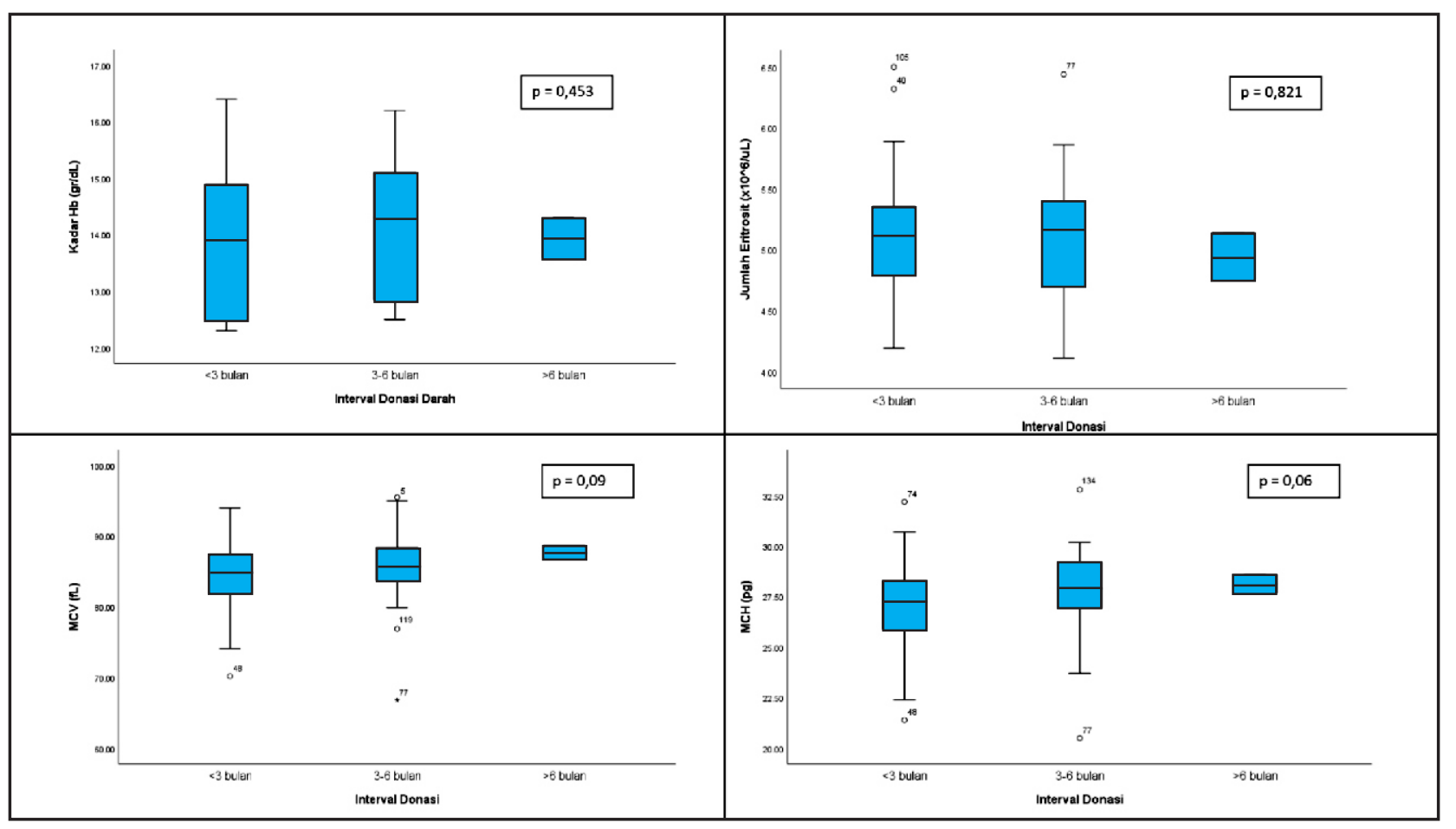

Figure 2. Hematology parameter based on blood donation interval

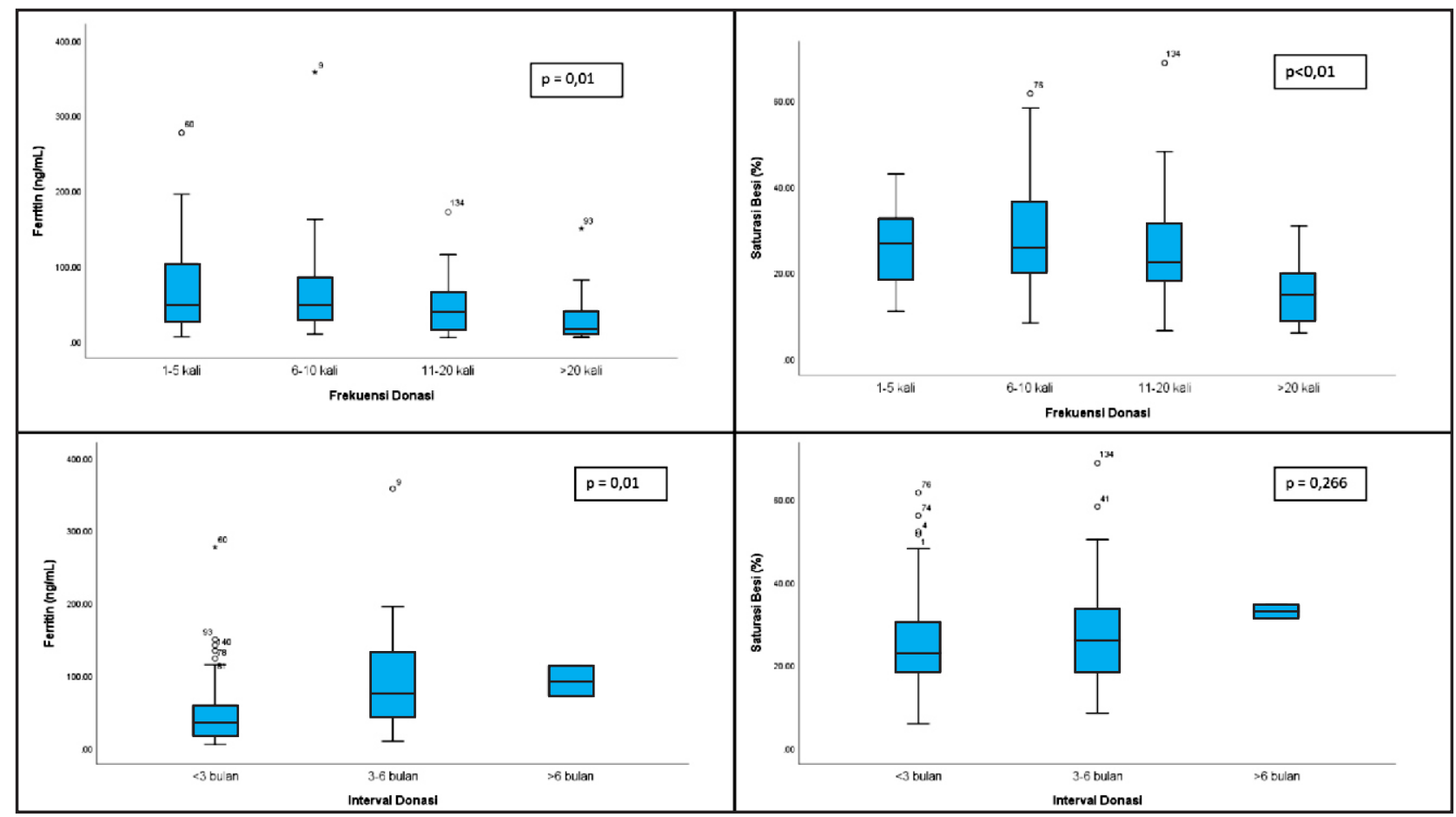

Figure 3. Ferritin and iron saturation based on blood donation frequency and interval 
$(\mathrm{MCH})$, showing that the levels decreased significantly with the frequency of blood donations $(27.6 \mathrm{pg}$ vs. $27.7 \mathrm{pg}$ vs. $27.8 \mathrm{pg}$ vs. $25.9 \mathrm{pg} ; \mathrm{p}=0.011$ ). However, there were no significant differences in measurement results in other hematological parameters, as erythrocytes count and hemoglobin between the donation frequency groups (see Figure 1 ).

In Figure 2, the results of the study subjects' routine hematology test regarding the interval between donations showed that all hematological parameters did not differ significantly between groups.

The results of iron status in subjects showed a consistent relationship in the frequency and interval of blood donations (see Figure 3). Significant decrease in ferritin levels was found with an increase in donation frequency ( $49.4 \mathrm{ng} / \mathrm{mL}$ vs. $48.3 \mathrm{ng} / \mathrm{mL}$ vs. $37.3 \mathrm{ng} / \mathrm{mL}$ vs. $16.9 \mathrm{ng} / \mathrm{mL}_{;} \mathrm{p}<0.01$ ) and shortening interval between donations $(35.01 \mathrm{ng} / \mathrm{mL}$ vs. $75.3 \mathrm{ng} / \mathrm{mL}$ vs. $92.7 \mathrm{ng} / \mathrm{mL} ; \mathrm{p}<0.01$ ). Iron saturation showed only significant differences in the frequency of blood donations. Iron saturation was found to decrease significantly with the increase in blood donation frequency ( $28.07 \%$ vs. $25.94 \%$ vs. $22.36 \%$ vs. $15.08 \%$; $\mathrm{p}<0.01$ ), but no significant difference was found at the interval blood donation $(26.92 \%$ vs. $26.04 \%$ vs. $33.03 \% ; p=0.226$ ).

Regular blood donation has long-term health implications for a decrease in the body's iron store. Donation frequency and the interval between donations and low compensation for restoring iron stores are closely related to the incidence of iron deficiency in this population. In this study, the study subjects were divided based on the characteristics of their blood donations. Complete blood count and iron status were evaluated based on the frequency and interval of blood donations.

It was found in this study that the erythrocyte index $(\mathrm{MCV}$ and $\mathrm{MCH})$ had the lowest significance at the donation frequency $>20$ times group. In contrast, the hemoglobin and erythrocytes counts were consistently found not significantly different in both groups, frequency, and donation interval. Previous studies supported a correlation between a decrease in the erythrocyte index and frequent donors, although not statistically significant. ${ }^{7}$ However, a study by Reddy et al. found that the lowest hemoglobin and erythrocyte levels were significant at the donation frequency $>20$ times, but there was no correlation between $\mathrm{MCV}$ and $\mathrm{MCH}$ with the frequency of donations. ${ }^{8}$ All blood transfusion units still use hemoglobin parameters to determine donor selection to maintain the quality of blood products. According to several studies, this parameter is not a sensitive indicator for detecting iron deficiency but rather for indicating anemia in an individual.

The median ferritin found in this study was consistently significantly lower in the group of subjects with the characteristics at the highest risk of deficiency. In a group with a donation frequency of $>20$ times, it was found that they had median ferritin of $16.9 \mathrm{ng} / \mathrm{mL}$ while the inter-donation interval < 3 months was $35.01 \mathrm{ng} / \mathrm{mL}$. The criteria for iron deficiency can be confirmed if a ferritin level $<20$ $\mathrm{ng} / \mathrm{mL}$ is found. Therefore, iron deficiency in this study was only detected at a donation frequency of $>20$ times. In addition, it can be assumed that at the donation frequency of 10 times or more, iron deficiency has occurred in the early stages that early detection can be performed in the donation frequency group. Reddy et al. found that the decreased iron stores could be detected after the fifth donation. ${ }^{7}$

It was found that the iron saturation parameter in this study had a significant relationship with the frequency of donations but not with the donation interval. Subjects with a donation frequency of $>20$ times were significantly lower saturation among the other groups (15.08\%). Iron deficiency is a condition in the iron saturation below $20 \%$. Therefore, if the basis for determining iron deficiency using iron saturation criteria is the same as ferritin, the initial detection can be performed before the $20^{\text {th }}$ donation, $10^{\text {th }}$ donation, or more.

The blood transfusion unit must have a responsibility to protect blood donors, including preventing and early detection of iron deficiency. The interval between donations, behavior, nutritional intake, and iron supplementation is essential, especially for donors with high-risk donation characteristics. The ferritin level has significantly decreased in repeated donations more than six times with a donation interval every three months; therefore, it is recommended to do screening for detection of iron deficiency. It is proven that early supplementation will significantly help restore iron stores if ferritin decreases. ${ }^{9,10}$

This study has superiority in controlling subjects related to inflammatory conditions. Serum ferritin and iron are known as acute phase reactants whose levels will be increased in inflammatory diseases. Subjects with CRP levels above $10 \mathrm{mg} / \mathrm{L}$ were excluded, that all subjects were confirmed to be in good health without inflammation. However, the daily iron intake can interfere with the measurement 
of iron saturation and is difficult to control. Furthermore, the demographic characteristics of donors were not considered in the study, that confounding factors related to these demographics were difficult to control.

\section{CONCLUSIONS AND SUGGESTIONS}

Serum ferritin levels were consistently lower in the group of subjects with the highest risk of iron deficiency, frequency of donations more than 20 times with an interval between donations less than three months compared to routine hematology parameter and iron saturation. In addition, the decrease in erythrocyte index was related to the frequency of donation; however, there was no change in hemoglobin and the number of erythrocytes in the donation characteristic stratification.

Routine ferritin evaluation needs to be done to detect a decrease in iron stores in blood donor populations, especially in high frequency and short interval donation. It is crucial to prevent this population from falling into a state of iron deficiency, which results in a decrease in the number of potential regular donors and disruption in blood supply.

\section{REFERENCES}

1. World Health Organization. Report on gender distribution of blood donors by country. WHO Global
Database on Blood Safety, 2016; 2-5.

2. Cable RG, Brambilla D, Glynn SA, Kleinman S, Mast AE, et al. Effect of iron supplementation on iron stores and total body iron after whole blood donation. Transfusion, 2016; 56(8): 2005-12.

3. Kiss JE, Birch RJ, Steele WR, Wright DJ, Cable RG. Quantification of body iron and iron absorption in the REDS-II Donor Iron Status Evaluation (RISE) study. Transfusion, 2017; 57(7): 1656-64.

4. Singh A, Chaudhary R, Sonker A, Pandey HC. Importance of donor history of restless leg syndrome and pica to assess iron deficiency. Transfus. Apr. Sci. 2016; 54(2): 259-61.

5. Goldman M, Magnussen K, Gorlin J, Lozano M. International forum regarding practices related to donor hemoglobin and iron. Vox Sang, 2016; 111(4): 449-455.

6. Tailor HJ, Patel PR, Kumar A, Pandya NP, Mangukiya S. Study of various hematological parameters and iron status among voluntary blood donors. Int J Med. Public Health, 2017; 7(1): 61-65.

7. Karakul O, Sommart P, Tolahan S, Poophapun W. Iron Supplements and Iron Status in Frequent Blood Donors. Hematol Transfus Int J. 2017; 5(3): 257-260.

8. Reddy VK, Shastrya S, Raturic M, Poornima BB. Impact of regular whole-blood donation on body iron stores. Transfus Med Hemother, 2020; 47: 75-79.

9. Kiss JE, Vassallo RV. How do we manage iron deficiency after blood donation?. British Journal of Haematology, 2018; 181: 590-603.

10. Lee SJ, Min HK, Jang JS, Lee S, Chung Y, Kim MJ. Donor protection: Iron supplementation for frequent blood donors in Korea. Trans and Aph Sci, 2020; 59: 102611. 